\title{
MicroRNA-I 24-3p inhibited progression of nasopharyngeal carcinoma by interaction with PCDH8 and the inactivation of PI3K/AKT/mTOR pathway
}

Jiacai Ye ${ }^{1,2}$, Quanxing Liao ${ }^{4}$, Xiaohui Zeng 3 , Chang Liu ${ }^{4}$, Yan Ding², Xuefeng Liu ${ }^{3}$, Lisi Zeng ${ }^{3 凶 *}$, Tianpei Guan $^{4 \bowtie *}$, Yawei Yuan ${ }^{1,2 \bowtie *}$

1. Department of Radiation Oncology, Nanfang Hospital, Southern Medical University, Guangzhou, China.

2. Department of Radiation Oncology, Affiliated Cancer Hospital and Institute of Guangzhou Medical University, Guangzhou, China.

3. Institute of Oncology, Affiliated Cancer Hospital \& Institute of Guangzhou Medical University, Guangzhou, China.

4. Department of Abdominal Surgery (Section 2), Affiliated Cancer Hospital \& Institute of Guangzhou Medical University, Guangzhou, China.

* These authors jointly supervised this work.

$\triangle$ Corresponding authors: Dr. Yawei Yuan, Department of Radiation Oncology, Nanfang Hospital, Southern Medical University, Guangzhou, China, Email: yuanyawei@gzhmu.edu.cn; Tianpei Guan, Affiliated Cancer Hospital \& Institute of Guangzhou Medical University, Guangzhou, China, 510095, Email: Dr_guan@126.com; Lisi Zeng, Affiliated Cancer Hospital \& Institute of Guangzhou Medical University, Guangzhou, China, 510095, Email: lisizeng@gzhmu.edu.cn

(c) The author(s). This is an open access article distributed under the terms of the Creative Commons Attribution License (https://creativecommons.org/licenses/by/4.0/). See http://ivyspring.com/terms for full terms and conditions.

Received: 2020.12.14; Accepted: 2021.05.31; Published: 2021.06.11

\begin{abstract}
Nasopharyngeal carcinoma (NPC) is characterised by distinct geographical distribution and is particularly prevalent in Asian countries. But the mechanisms related to the progression of nasopharyngeal carcinoma (NPC) are not completely understood. MiR-124-3p functions as a tumor suppressor in many kinds of human cancers. Here, we explored the effects and mechanism of miR-I 24-3p on the proliferation and colony formation in NPC. In our study, we reported that miR-124-3p was significantly downregulated in NPC tissues and cell lines. Overexpression miR-124-3p decreased NPC cell proliferation and colony formation abilities. Meanwhile, knockdown miR-124-3p increased proliferation and colony formation abilities. Additionally, dual-luciferase assay showed that miR-124-3p could positively regulated PCDH8 by targeting its 3'-UTR. Overexpression of $\mathrm{PCDH} 8$ could partially rescue the proliferation and colony formation role of miR-124-3p inhibitor. Our study indicated that miR-I24-3p played a tumor suppressor by directly interacting with PCDH8 and inhibiting the activation of the phosphatidylinositol 3-kinase (PI3K)/AKT/mammalian target of rapamycin (mTOR) signaling pathway. Overall, we found that miR-124-3p inhibited the activation of the PI3K/AKT/mTOR signaling pathway in NPC by interacting with PCDH8. Thus, PCDH8 may be a potential molecular target that impeded NPC proliferation and colony formation.
\end{abstract}

Key words: MicroRNA-124-3p, tumor proliferation, growth, nasopharyngeal carcinoma, protocadherin-8, phosphatidylinositol 3-kinase/AKT/mammalian target of rapamycin

\section{Introduction}

Nasopharyngeal carcinoma (NPC) is a malignant type of head and neck squamous cell carcinoma occurring in epithelial cells of the nasopharynx $[1,2]$. NPC is associated with distinct geographical distribution and racial differences, and it is highly prevalent in Asian countries [3, 4]. NPC is prone to invasion and distant metastasis at an early stage, and more than $70 \%$ of patients are diagnosed with advanced NPC during their initial assessment [5]. NPC is sensitive to radiotherapy; thus, this treatment strategy has greatly improved local control of lesions and the 5-year survival rate in patients with NPC [5-8]. However, frequent local recurrence, metastasis, and poor prognosis remain major challenges in the clinical treatment of NPC because the mechanisms related to NPC progression are not completely understood [9-11].

MicroRNAs (miRNAs) play critical roles as oncogenes or tumor suppressors in NPC. MiRNAs are a category of small non-coding RNAs ( $19-25$ 
nucleotides) that regulate essential biological processes by directly interacting with their target mRNAs at 3'-untranslated regions (3'-UTRs) [12-15]. Recent studies have reported that multiple miRNAs (e.g., $m i R-26 a, m i R-101$, $m i R-98$, and $m i R-214$ ) are abnormally expressed in patients with NPC and contribute to the development and progression of NPC [16-19]. MiR-124-3p is the mature sequence of $m i R-124$ in humans and acts as a tumor suppressor in some cancer types, such as esophageal squamous cell carcinoma and glioma [20, 21]. Furthermore, miR-124 played essential roles in the development and progression of NPC [22-27]. Xu et al. demonstrated that NPC growth and metastasis were inhibited by the overexpression of miR-124-3p [28]. Nevertheless, the potential function and mechanism of tumor suppression remain unclear.

Protocadherin- 8 (PCDH8) is predicted to be a target of miR-214-3p using targetscan (http://www.targetscan.org). PCDH8 is an integral membrane protein that acts as a tumor suppressor in several types of cancer [29-31] and is involved in the metastasis of gastric cancer [32]. Additionally, PCDH8 has been found to be regulated by miR-217, which promotes apoptosis in small cell lung cancer [33]. PCDH8 also plays tumor-suppressive roles in NPC [34].

In this study, function assays found that overexpression of miR-124-3p decreased NPC cell proliferation and colony formation abilities, meanwhile knockdown of $m i R-124-3 p$ increased proliferation and colony formation abilities. Mechanism assays indicated that $m i R-124-3 p$ played a tumor suppressor by directly interacting with PCDH8 and inhibiting the activation of PI3K/AKT/mTOR signaling pathway.

\section{Materials and Methods}

\section{Cell culture}

The human nasopharyngeal epithelial cell line NP69 and four human NPC cell lines (CNE2, 6-10B, S18, and HK1) were obtained from Guangzhou Medical University Surgical Laboratory (Guangzhou, China) and cultured in Roswell Park Memorial Institute-1640 (RPMI-1640; Gibco, Rockville, MD, USA) medium containing $10 \%$ fetal bovine serum (Gibco Life Technologies, Rockville, MD, USA) and $1 \%$ penicillin/streptomycin (Gibco). All cell lines were cultured at $37^{\circ} \mathrm{C}$ with $5 \%$ carbon dioxide.

\section{Cell transfection}

Hsa-miR124-3p mimics and inhibitor lentiviral packaging constructs were obtained from GenePharma Biotechnology Co., Ltd. (Shanghai, China). For cell transfection, cells were seeded into six-well plates, and lentivirus (50 $\mu \mathrm{L}$ "lv-mir124-3p mimic" or $50 \mu \mathrm{L}$ "lv-mir124-3p inhibitor") and $3 \mu \mathrm{L}$ polybrene were added to each well. Puromycin $(2.0$ $\mathrm{mg} / \mathrm{mL}$ ) was then added to each well, and plates were incubated for 14 days to select cells with stable expression of constructs. Cells infected with lentiviral nonsense scramble control miRNA were used as the control.

\section{RNA isolation and quantitative polymerase chain reaction (PCR)}

Total RNA from NPC cell lines and tumor tissue from xenograft were extracted from cells using TRIzol reagent (Invitrogen, Carlsbad, CA, USA). The quality and concentration of total RNA were measured using a NanoDrop 2000 spectrophotometer (Thermo Scientific, USA). The GoScript Reverse Transcription System (Promega, Madison, WI, USA) was used for cDNA synthesis from $2 \mu \mathrm{g}$ of total RNA. Real-time quantitative PCR was performed with $2 \mu \mathrm{L}$ cDNA template and $7.5 \mu \mathrm{L}$ GoTaq quantitative PCR Master Mix (Promega) in a $15-\mu \mathrm{L}$ total reaction volume. Samples were processed on a CFX96 Touch Real-Time PCR Detection system (Bio-Rad Laboratories, Hercules, CA, USA) using the manufacturer's protocol. Primers were synthetized by Shanghai Thermo Fisher Company (Shanghai, China). Glyceraldehyde 3-phosphate dehydrogenase $(G A P D H)$ and $U 6$ genes were used as internal standards. The following primers were used: GAPDH forward primer, 5'-CTCCTCCTGTTCGACAGT CAGC-3'; GAPDH reverse primer, 5'-CCCAATACG ACCAAATCCGTT-3'; U6 forward primer, 5'-CTC GCTTCGGCAGCACA-3'; U6 reverse primer, 5'-AAC GCTTCACGAATGCGT-3'; miR-124-3p forward primer, 5'-CTCAACTGGTGTCGTGGAGTCGGCAAT TCAGTTGAGGGCATTCA-3'; miR-124-3p reverse primer, 5'-ACACTCCAGCTGGGTAAGGCACGC GGTGAATGCC-3'; $\mathrm{PCDH8}$ forward primer, 5'-TATGGGCACGAGCACTTCC-3'; $\mathrm{PCDH8}$ reverse primer, 5'-CCAGCGTCAAGTTGTACTCGG-3'. All experiments were performed in triplicate and relative expression was calculated using the $2^{-\Delta \Delta \mathrm{Ct}}$ method.

\section{Cell Counting Kit-8 (CCK-8) assay}

The proliferative activity of cells was detected by CCK-8 assays (Dojindo Laboratories, Kumamoto, Japan). NPC cells were collected during the logarithmic phase, and then cell suspension was incubated in a 96 -well plate $\left(3 \times 10^{3}\right.$ cells $/$ well $)$ at $37^{\circ} \mathrm{C}$ in 5\% CO2 overnight, until all cells adhered to the wall.After cell attachment, transfection was performed using Lipofectamine 3000 and P3000 (Invitrogen) according to the manufacturers instructions. After transfection for $0,24,48,72,96$, or 
$120 \mathrm{~h}, 10 \mu \mathrm{L}$ CCK-8 solution was added to each well, and the cells were incubated for $2 \mathrm{~h}$ at $37^{\circ} \mathrm{C}$. The absorbance of each well was detected at $450 \mathrm{~nm}$ using a multifunctional microplate reader.

\section{Colony formation assay}

The colony-forming activity of cells was examined by colony formation assay. NPC cells of logarithmic growth phase were collected and plated into 12-well plates (100 cells/well. All cells were cultured and maintained at $37^{\circ} \mathrm{C}$ in an incubator with $5 \%$ CO2. Twelve days after seeding, the cells were washed with $P B S$ thrice and fixed with methanol for $10 \mathrm{~min}$. After fixation, cells were washed three times with PBS. Then the colonies containing more than 50 cells was counted after staining with crystal violet.

\section{Western blotting}

Lysis buffer containing a protease inhibitor was used for processing NPC cell protein extracts. The protein concentration of each sample was measured with a bicinchoninic acid protein assay kit (KenGEN BioTECH, Nanjing, China). First, $30 \mu \mathrm{g}$ of each protein sample was separated using sodium dodecyl sulfatepolyacrylamide gel electrophoresis and transferred to polyvinylidene difluoride membranes. The membranes were blocked with 5\% skimmed milk for $2 \mathrm{~h}$ at room temperature and incubated with primary antibodies at $4^{\circ} \mathrm{C}$ overnight. The primary antibodies were used for western blotting (Supplementary table S1). The membranes were washed three times with Tris-buffered saline and Tween-20 and then incubated at room temperature for $2 \mathrm{~h}$ with horseradish peroxidase-conjugated secondary antibodies (anti-rabbit or anti-mouse; Cell Signaling Technology). $\beta$-Tubulin was used as an endogenous control to compare the protein expression. A chemiluminescence system (Tanon 5200; Tanon Science \& Technology Co., Ltd., Shanghai, China) was used to visualize the proteins on the membranes.

\section{Dual-luciferase reporter assay}

Cells were seeded into 24-well plates to examine the relationships between miR-124-3p and PCDH8. Cells were cotransfected with $200 \mathrm{ng}$ PCDH8 (wild-type [WT]) or PCDH8 (mutant [MUT]) reporter plasmids and $20 \mathrm{nM}$ miR-NC or miR-124 with Lipofectamine 3000 reagent (Invitrogen). The firefly and Renilla luciferase activities were measured using a dual-Glo luciferase reporter assay kit (Promega).

\section{Tumor growth in xenograft model}

All animal experiments were conducted under protocols approved by the Animal Experimentation Ethics Committee of Guangzhou Medical University (No.2005DKA21300). 6 8-week old immunodeficient
BABL/c nude mice were used assay as a xenograft model for tumor growth. Cells were counted $\left(5 \times 10^{6}\right)$ and injected into the right dorsal flank of BABL/c nude mice. The weight of mice and volume of tumor were measured every 4 days, tumor volume was calculated using the formula: Tumor maximum diameter $(\mathrm{L}) \times$ the right-angle diameter to that axis $(\mathrm{W})^{2} / 2$. After 4 weeks of injection, mice were sacrificed according to institutional ethical guidelines, the xenograft tumors were dissected and weighted comparing to control groups in vivo.

\section{In situ hybridization (ISH)}

In situ hybridization was performed using single-strand RNA probes comprising antisense or sense sequences of decorin or biglycan. Digoxigenin (DIG)-labeled RNA probes were synthesized by in vitro transcription with microRNA ISH Buffer using a DIG RNA Labeling Kit (Roche). Chip HLugA180Su01 were fixed and hybridized with RNA probes. Hybridization signals were detected immunohistochemically by anti-DIG-AP Fab fragments. The reagents used are shown in Supplementary table S2.

\section{Immunohistochemistry (IHC)}

IHC for target molecules (PCDH8) was performed on sections from tumor tissues of nude mice xenografts. Tissue sections were deparaffinized, subjected to antigen retrieval using $0.01 \mathrm{M}$ sodium citrate solution, and incubated with immunohistochemical ultrasensitive kit (MXB Biotechnologies, Fuzhou, China) and primary antibodies against PCDH8. Then sections were incubated with 3,3Diaminobenzidine (DAB). Quantification of PCDH8 was measured by intensity and extent of staining.

\section{Statistical analysis}

Data were analyzed using Statistical Product and Service Solutions version 20.0 (IBM Corp., Armonk, NY, USA). The differences between two groups were compared with Student's $t$-tests or Pearson's $\chi^{2}$-tests. One-way analysis of variance was used for comparisons of multiple groups. P value of $<0.05$ was considered as a statistically significant difference.

\section{Results}

\section{miR-124-3p was expressed at low levels in NPC tissues and cell lines}

The miRbase website (http://mirbase.org/) showed that the expression of $m i R-124-3 p$ in head and neck squamous cell carcinoma tissues was significantly downregulated (Fig. 1A), which indicated miR-124-3p may play a tumor suppressor role in tumorigenesis. To further evaluate the expression of miR-124-3p, qPCR showed that the 
expression of miR-124-3p was significantly downregulated in NPC cell lines, especially 6-10B and CNE2 cell lines (Fig. 1B). To further explore the importance of miR-124-3p in clinically, NPC tissue microarray (Chip HLugA180Su01) was used in situ hybridization. In order to explore the relationship between miR-124-3p and clinical parameters of NPC patients, NPC patients were divided into two groups: high expression group and low expression group according to the median expression of miR-124-3p. The correlation between the expression of miR-124-3p and clinicopathological data was analyzed. We analyzed the effect of high and low expression of miR-124-3p on the overall survival (OS) and recurrence-free survival (RFS) in patients with NPC. The results showed that compared with patients with lower expression of miR-124-3p, NPC patients with higher expression of miR-124-3p had significantly longer 5-year OS and 5-year RFS (Fig. $1 \mathrm{C}$ and D). Cox and multivariate cox regression analysis showed that miR-124-3p, clinical stage was correlated with prognosis (Table 1 , Table 2 and $2 \mathrm{~A}$ ).

A

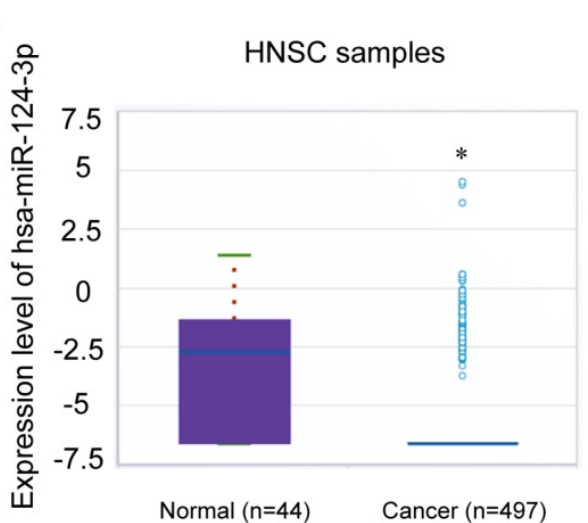

C

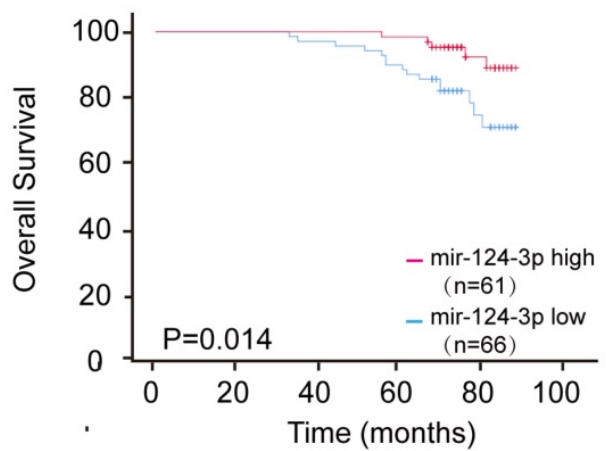

B

D
Upregulation of miR-124-3p decreased proliferation and colony formation in NPC cells

To explore the potential role of $m i R-124-3 p$ in NPC, cells were transfected with miR-124-3p mimic, accordingly, miR-124-3p could be upregulated in 6-10B and CNE2 cells (Fig. 2A). To know the function of miR-124-3p, function assays were further explored. As shown in Fig. 2B and 2C, after overexpression of miR-124-3p, cell proliferation were significantly decreased in the miR-124-3p mimic group compared with those in the mimic negative control (NC) group $(\mathrm{P}<0.05)$. Similarly, after overexpression of miR-124-3p, colony formation was significantly decreased in the miR-124-3p mimic group compared with those in the mimic negative control (NC) group $(\mathrm{P}<0.05$; Fig. 2D and 2E). To further evaluation the role of miR-124-3p expression on proliferation, western blotting was used to detect the proliferation related protein. As shown in Fig. 2F, overexpression of miR-124-3p in CNE2 and 6-10B cells caused a decrease in cyclin D3 and cyclin-dependent kinase 4 protein levels (CDK4). Thus, these results indicated that miR-124-3p affected cell progression by regulating the expression of cyclin D3 and CDK4.
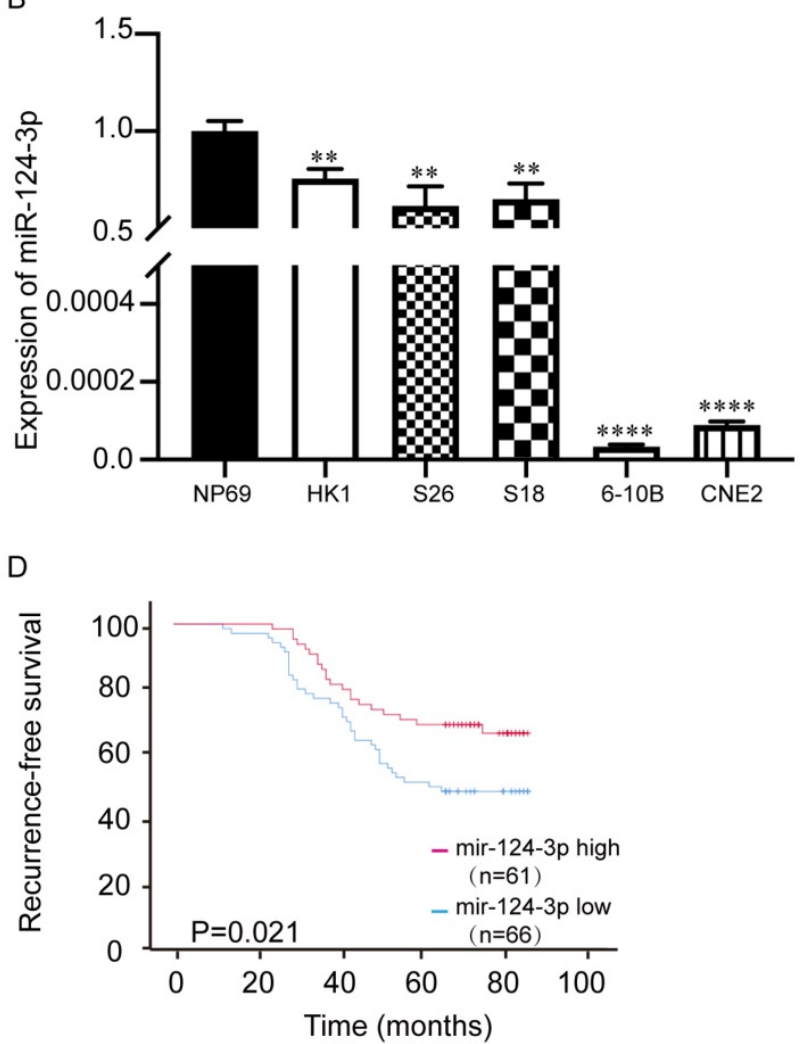

Figure 1. miR-124-3p expression was decreased in nasopharyngeal carcinoma tissues and cell lines compared with that in normal tissues. (A) Expression of miR-124-3p in head and neck squamous cell carcinoma compared to that in healthy tissues. (B) Expression of miR-I24-3p in CNE2, 6-10B, S18, and HK1 cells. (C) Overall survival of nasopharyngeal carcinoma (NPC) patients with high or low miR-I24-3p. (D) Recurrence-free survival (RFS) of NPC patients with high or low miR-I24-3p. Higher miR-124-3p expression was associated with higher OS and RFS. 


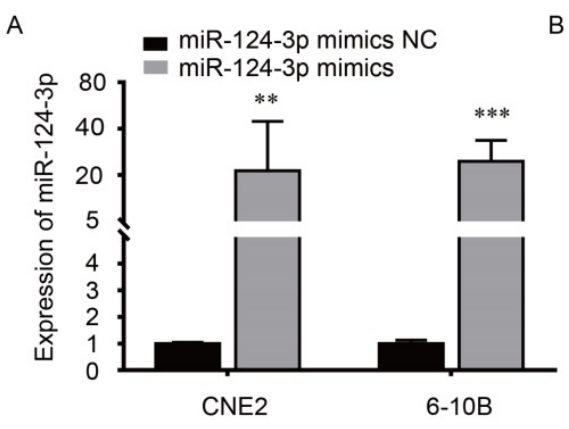

D

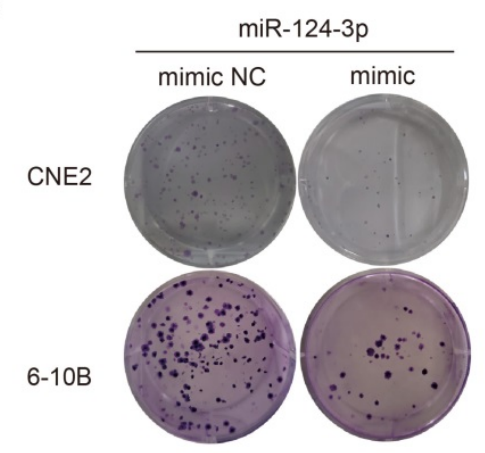

B

E
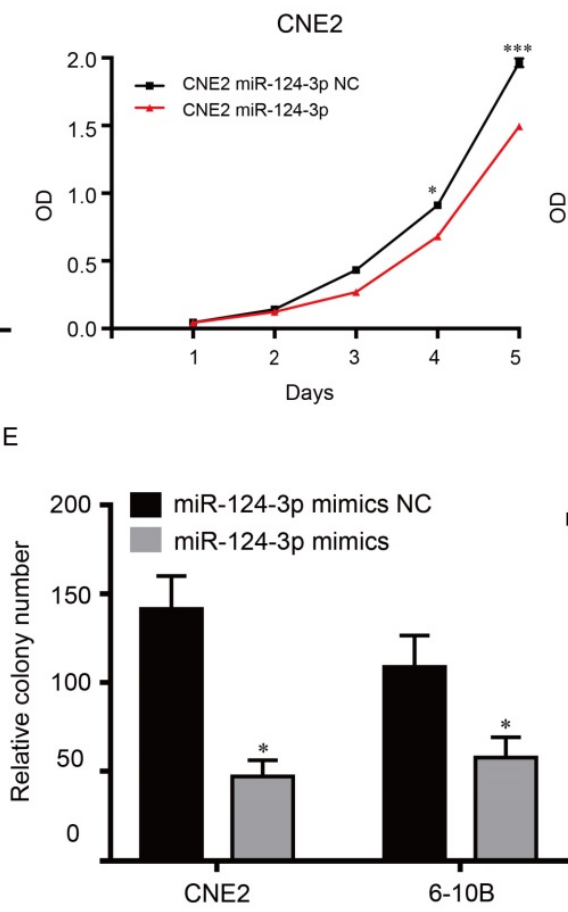

C

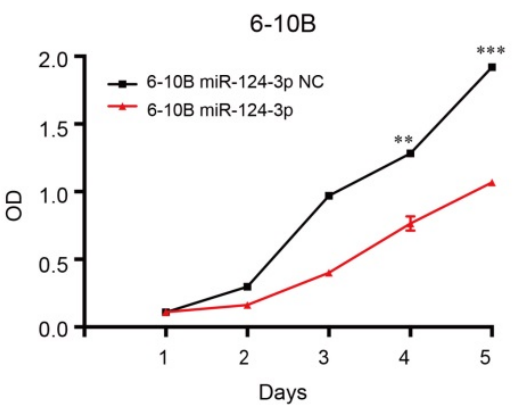

F

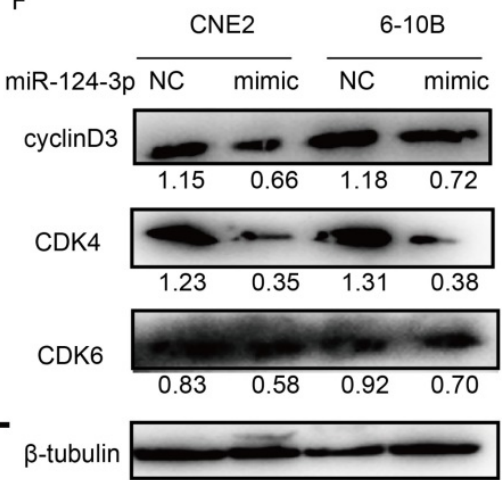

Figure 2. Upregulation of miR-124-3p expression decreased cell proliferation and colony formation in nasopharyngeal carcinoma cells. (A) Effects of miR-124-3p mimic on miR-124-3p expression in CNE2 and 6-10B cells. (B and C) Effects of miR-124-3p overexpression on CNE2 and 6-10B cell proliferation, as evaluated using CCK-8 assays. (D and E) Effects of miR-1 24-3p overexpression on colony formation in CNE2 and 6-10B cells, as evaluated using plate cloning. (F) Effects of miR-I24-3p overexpression on cyclin D3 and CDK4 expression in CNE2 and 6-10B cells, as determined by western blotting.

Table 1. Correlation between mir-124-3p expression and clinicopathological characteristics.

\begin{tabular}{|c|c|c|c|c|c|c|}
\hline & \multirow[t]{2}{*}{ Variables } & \multicolumn{2}{|c|}{$\begin{array}{l}\text { Mir-124-3p } \\
\text { expression }\end{array}$} & \multirow[t]{2}{*}{ Total } & \multirow[t]{2}{*}{$x^{2}$} & \multirow[t]{2}{*}{$\mathrm{p}$ value } \\
\hline & & Low & High & & & \\
\hline \multirow[t]{3}{*}{ Age (year) } & & & & & 0.044 & 0.835 \\
\hline & $<=45$ & 28 & 27 & 55 & & \\
\hline & $>45$ & 38 & 34 & 72 & & \\
\hline \multirow[t]{4}{*}{ Stage } & & & & & 2.444 & 0.118 \\
\hline & $\mathrm{I} / \mathrm{II}$ & 32 & 38 & 70 & & \\
\hline & III/IV & 34 & 23 & 57 & & \\
\hline & Null & & & & & \\
\hline \multirow{4}{*}{$\begin{array}{l}\text { Cervical lymph node } \\
\text { metastasis }\end{array}$} & & & & & 0.006 & 0.94 \\
\hline & No & 18 & 17 & 35 & & \\
\hline & Yes & 48 & 44 & 92 & & \\
\hline & Null & & & & & \\
\hline \multirow[t]{4}{*}{ Sex } & & & & & 1.654 & 0.198 \\
\hline & Female & 13 & 18 & 31 & & \\
\hline & Male & 53 & 43 & 96 & & \\
\hline & Null & & & & & \\
\hline
\end{tabular}

Table 2. Univariate and multivariate analyses of the expression of mir-124-3p correlated with overall survival and recurrence-free survival. (1) The expression of mir-124-3p correlated with overall survival.

\begin{tabular}{lllllll}
\hline Variables & \multicolumn{2}{l}{ Univariate analysis } & \multicolumn{4}{c}{ Multivariate analysis } \\
\hline & HR & $95 \% \mathrm{CI}$ & $\mathrm{p}$ value & HR & $95 \% \mathrm{CI}$ & $\mathrm{p}$ value \\
\hline Expression & 0.303 & $0.11-0.837$ & 0.021 & 0.303 & $0.109-0.842$ & 0.022 \\
Sex & 0.863 & $0.313-2.375$ & 0.775 & & & \\
Age & 1.249 & $0.51-3.057$ & 0.626 & & & \\
Stage & 8.121 & $3.763-17.529$ & $<0.001$ & 9.151 & $4.061-20.623$ & $<0.001$ \\
\hline
\end{tabular}

Table 2A. Univariate and multivariate analyses of the expression of mir-124-3p correlated with overall survival and recurrence-free survival. (2) The expression of mir-124-3p correlated with recurrence-free survival.

\begin{tabular}{lllllll}
\hline Variables & \multicolumn{2}{l}{ Univariate analysis } & \multicolumn{4}{c}{ Multivariate analysis } \\
\hline & $\mathrm{HR}$ & $95 \% \mathrm{CI}$ & $\mathrm{p}$ value & $\mathrm{HR}$ & $95 \% \mathrm{CI}$ & $\mathrm{p}$ value \\
\hline Expression & 0.536 & $0.313-0.92$ & 0.024 & 0.63 & $0.366-1.083$ & 0.095 \\
Sex & 1.434 & $0.743-2.769$ & 0.283 & & & \\
Age & 1.31 & $0.768-2.234$ & 0.321 & & & \\
Stage & 2.504 & $1.821-3.444$ & $<0.001$ & 2.435 & $1.765-3.36$ & $<0.001$ \\
\hline * Statistically significant $(\mathrm{p}<0.05)$ & & & &
\end{tabular}

\section{Knockdown miR-124-3p increased proliferation and colony formation in NPC cells}

In similar opposite way, to explore the potential role of $m i R-124-3 p$ in NPC, cells were transfected with $m i R-124-3 p$ inhibitor, miR-124-3p could also be knockdown in S18 and HK1 cells (Fig. 3A). The function of miR-124-3p assays were also further explored. As shown in Fig. 3B and 3C, after down expression of miR-124-3p, cell proliferation were significantly increased in the miR-124-3p mimic group compared with those in the mimic negative control (NC) group $(\mathrm{P}<0.05)$. Similarly, after down expression of miR-124-3p, colony formation were significantly increased in the miR-124-3p inhibitor group compared with those in the mimic negative control (NC) group $(\mathrm{P}<0.05$; Fig. $3 \mathrm{D}$ and $3 \mathrm{E})$. To 
further evaluation the role of miR-124-3p expression on proliferation, western blotting was used to detect the proliferation related protein. As shown in Fig. 3F, down expression of miR-124-3p in S18 and HK1 cells caused a decrease in P27 and an increase in cyclin-dependent kinase 6 protein levels (CDK6). Thus, these results indicated that miR-124-3p affected cell progression by regulating the expression of $\mathrm{P} 27$ and CDK6.

\section{miR-I24-3p positively regulated PCDH8 by targeting its 3'-UTR}

To explore the potential target of $m i R-124-3 p$, the target genes of $m i R-124-3 p$ were investigated using TargetScan (http://www.targetscan.org/). The results showed that the $3^{\prime}$-UTR sequence in $P C D H 8$ may be a binding target of miR-124-3p (Fig. 4A). Dual-luciferase assay showed that, compared with that in the NC group, after transfected with the PCDH8-WT plasmid in 293T cells, the firefly luciferase activity of $m i R-124-3 p$ significantly increased. However, cells transfected with the PCDH8-MUT plasmid, the firefly luciferase activity was significantly changed (Fig. 4B). And we found the same phenomenon in S18 cells (Fig. 4C). Moreover, qPCR and western blotting showed that overexpression of miR-124-3p significantly increased the mRNA and protein level of PCDH8 $(P<0.01$; Fig. $4 \mathrm{D}$ and $4 \mathrm{E})$, whereas miR-124-3p inhibition could decrease the mRNA and protein of PCDH8 $(P<0.01$; Fig. $4 \mathrm{~F}$ and $4 \mathrm{G})$. The expression of PCDH8 in CNE2 and $6-10 \mathrm{~B}$ cells were significantly upregulated in cells transfected with miR-124-3p mimic compared with those in the mimic NC group. These results indicated that PCDH8 miR-124-3p, miR-124-3p may suppress the NPC proliferation by regulating PCDH8 transcriptional activity.

\section{PCDH8 rescued tumor suppressor role of miR-1 24-3p}

PCDH8 plasmids were transfected into NPC cell lines to explore the relationship between PCDH8 expression and miR-124-3p. Treatment with $m i R-124-3 p$ inhibitor markedly promoted cell proliferation in S18 (Fig. 5A) and HK1 cells (Fig. 5B) endogenously expressing PCDH8. To determine whether ectopic overexpression of PCDH8 could rescue the suppressive effects of miR-124-3p on cell proliferation, $l v-m i R-124-3 p$ inhibitor was transfected into S18 and HK1 cells. We observed that the cell proliferation and colony formation were inhibited in the infected miR-124-3p inhibitor and PCDH8 plasmid group compared with those in the inhibitor vector control and inhibitor NC groups. Further, transfection with PCDH8 and mir-124-3p inhibitors impaired the ability of PC cell clone formation. (Fig. 5C and D). CCK8 and colony-forming assays showed that PCDH8 could partially reduce the miR-124-3p inhibitor-mediated activity in S18 and HK1 cells. To further explore the importance of PCDH8 in clinical survival, NPC tissue microarray (Chip HLugA180Su01) was used in immunohistochemistry. In order to explore the relationship between PCDH8 and clinical parameters of NPC patients, NPC patients were divided into two groups: high expression group and low expression group according to the median expression of PCDH8. The correlation between the expression of PCDH8 and clinicopathological data was analyzed. We analyzed the effect of high and low expression of PCDH8 on the OS and RFS in patients with NPC. The results showed that compared with patients with lower expression of PCDH8, NPC patients with higher expression of PCDH8 had significantly longer 5-year OS and 5-year RFS (Fig. $5 \mathrm{E}$ and F). PCDH8 and clinical parameters were analyzed by cox univariate and multivariate regression analysis to explore the prognostic factors. Clinically regression analysis demonstrated that PCDH8, clinical stage was also correlated with good OS and RFS (Table 3, Table 4 and $4 \mathrm{~A})$. Conjointly, these results suggested that PCDH8 could be used as potential biomarker to predict the prognosis of patients with NPC.

\section{miR-124-3p suppress tumor formation of NPC cells in mouse xenograft models}

To further investigate the effect of miR-124-3p on the proliferation of NPC cells in vivo. CNE2 cell with high expression of miR-124-3p were injected into the subcutaneous of nude mice. Compared with the control group, miR-124-3p overexpression resulted in a smaller size of the subcutaneous tumor in mice (Fig. $6 \mathrm{~A})$. And the mean tumor volume for miR-124-3p overexpression group was significantly smaller than NC group (Fig. 6B). Additionally, the weight of tumor tissue was lower in the miR-124-3p overexpression group than that of the NC group (Fig. 6C). Moreover, qRT-PCR analysis suggested that miR-124-3p expression was obviously increased in tumor tissue of miR-124-3p overexpressed nude mice. (Fig. 6D), and Western blotting assay showed that the protein of PCDH8 was increased when miR-124-3p overexpressed (Fig. 6E). Collectively, these results above suggested that miR-124-3p suppress proliferation of NPC cell in vivo. 

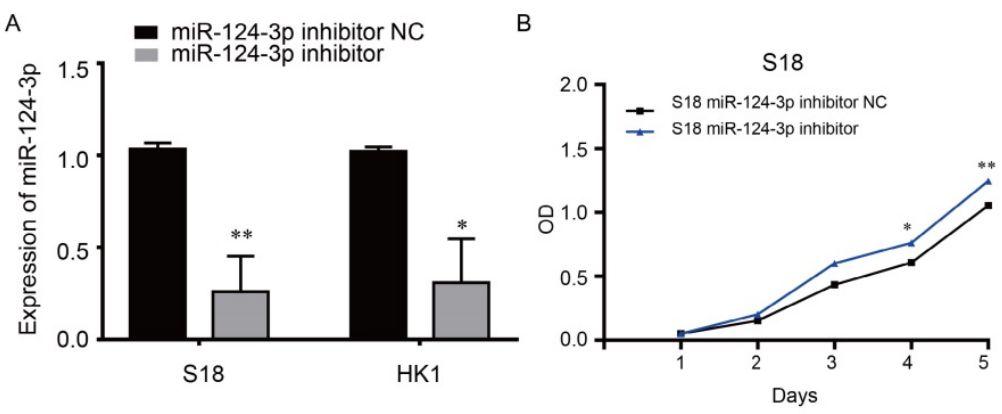

$$
\text { C }
$$
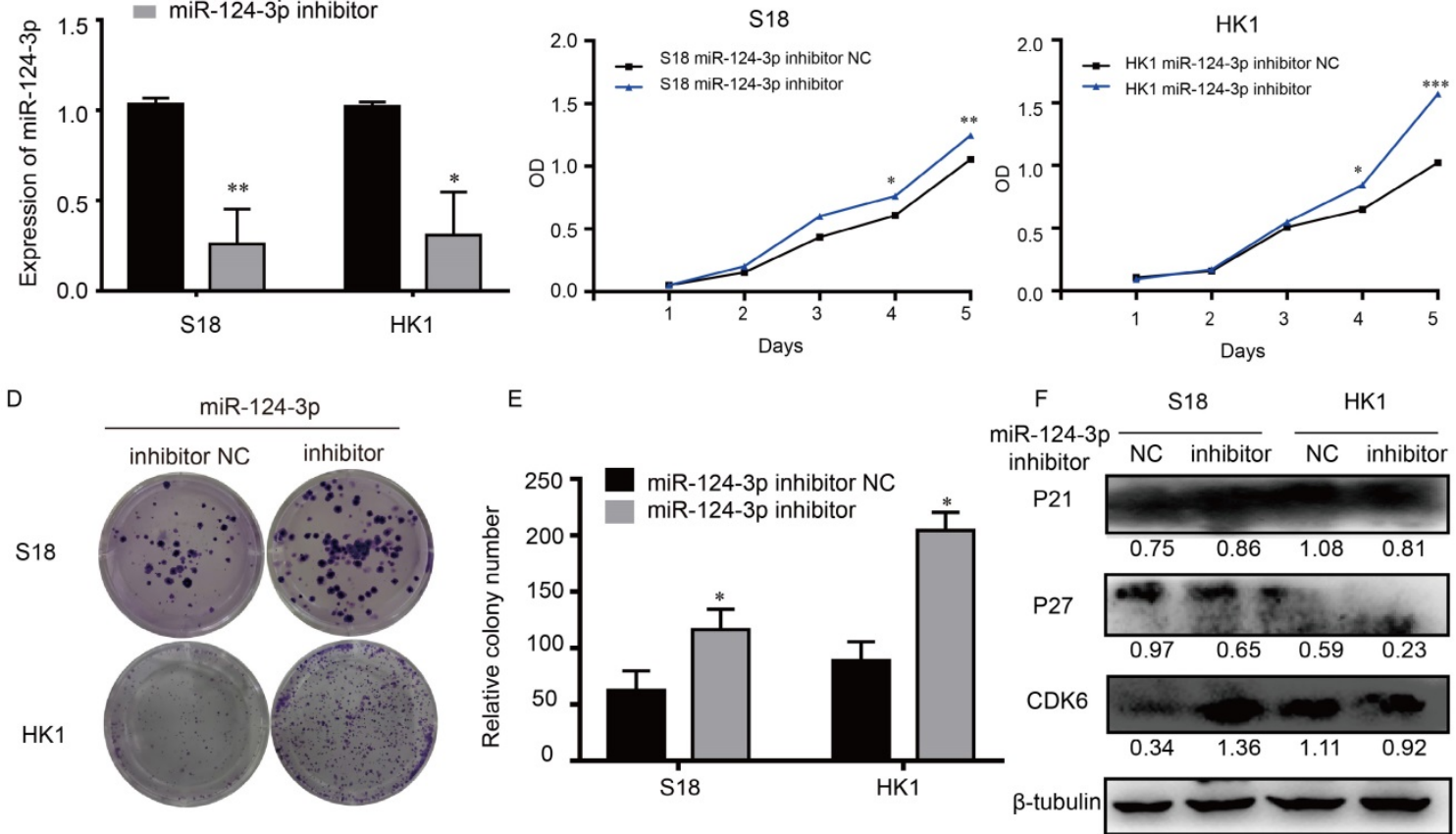

Figure 3. Knockdown miR-I24-3p expression increased cell proliferation and colony formation in nasopharyngeal carcinoma cells. (A) Effects of miR-124-3p inhibitor on miR-124-3p expression in S18 and HK1 cells. (B and C) Effects of miR-I24-3p down expression on S18 and HK1 cell proliferation, as evaluated using CCK-8 assays. (D and E) Effects of miR-I 24-3p down expression on colony formation in S18 and HK1 cells, as evaluated using plate cloning. (F) Effects of miR-I24-3p down expression on P21, P27 and CDK6 expression in $\mathrm{S} 18$ and HK1 cells, as determined by western blotting.

Table 3. Correlation between PCDH8 expression and clinicopathological characteristics.

\begin{tabular}{|c|c|c|c|c|c|c|}
\hline & \multirow[t]{2}{*}{ Variables } & \multicolumn{2}{|c|}{ PDH8 expression } & \multirow[t]{2}{*}{ Total } & \multirow[t]{2}{*}{$x^{2}$} & \multirow[t]{2}{*}{$\mathrm{p}$ value } \\
\hline & & Low & High & & & \\
\hline \multirow[t]{3}{*}{ Age (year) } & & & & & 0.585 & 0.444 \\
\hline & $<=45$ & 28 & 27 & 55 & & \\
\hline & $>45$ & 41 & 30 & 71 & & \\
\hline \multirow[t]{4}{*}{ Stage } & & & & & 0.412 & 0.521 \\
\hline & $\mathrm{I} / \mathrm{II}$ & 36 & 33 & 69 & & \\
\hline & III/IV & 33 & 24 & 57 & & \\
\hline & Null & & & & & \\
\hline \multirow[t]{4}{*}{ Cervical lymph node metastasis } & & & & & 0.75 & 0.387 \\
\hline & No & 17 & 18 & 35 & & \\
\hline & Yes & 52 & 39 & 91 & & \\
\hline & Null & & & & & \\
\hline \multirow[t]{4}{*}{ Sex } & & & & & 1.042 & 0.307 \\
\hline & Female & 14 & 16 & 30 & & \\
\hline & Male & 55 & 41 & 96 & & \\
\hline & Null & & & & & \\
\hline
\end{tabular}

Table 4. Univariate and multivariate analyses of the expression of PCDH8 correlated with overall survival and recurrence-free survival. (1) The expression of PCDH8 correlated with overall survival.

\begin{tabular}{lllllll}
\hline Variables & \multicolumn{2}{l}{ Univariate analysis } & \multicolumn{4}{c}{ Multivariate analysis } \\
\hline & $\mathrm{HR}$ & $95 \% \mathrm{CI}$ & $\mathrm{p}$ value & $\mathrm{HR}$ & $95 \% \mathrm{CI}$ & $\mathrm{p}$ value \\
\hline Expression & 0.212 & $0.062-0.727$ & 0.014 & 0.311 & $0.09-1.075$ & 0.065 \\
Sex & 1.067 & $0.354-3.217$ & 0.908 & & & \\
Age & 1.153 & $0.463-2.867$ & 0.76 & & & \\
Stage & 7.833 & $3.616-16.968$ & $<0.001$ & 7.146 & $3.314-15.409$ & $<0.001$ \\
\hline
\end{tabular}

Table 4A. Univariate and multivariate analyses of the expression of PCDH8 correlated with overall survival and recurrence-free survival. (2) The expression of $\mathrm{PCDH} 8$ correlated with recurrence-free survival.

\begin{tabular}{lllllll}
\hline Variables & \multicolumn{2}{l}{ Univariate analysis } & \multicolumn{4}{c}{ Multivariate analysis } \\
\hline & HR & $95 \% \mathrm{CI}$ & $\mathrm{p}$ value & $\mathrm{HR}$ & $95 \% \mathrm{CI}$ & $\mathrm{p}$ value \\
\hline Expression & 0.46 & $0.26-0.813$ & 0.008 & 0.612 & $0.342-1.095$ & 0.098 \\
Sex & 1.54 & $0.777-3.051$ & 0.216 & & & \\
Age & 1.285 & $0.751-2.197$ & 0.36 & & & \\
Stage & 2.505 & $1.815-3.459$ & $<0.001$ & 2.362 & $1.704-3.274$ & $<0.001$ \\
\hline
\end{tabular}

* Statistically significant $(\mathrm{p}<0.05)$

miR-124-3p inhibited NPC cell proliferation and growth by inactivating the PI3K/AKT/mTOR signaling pathway

Next, we evaluated the protein expression of components of the PI3K/AKT/mTOR signaling pathway, including PI3K, AKT, phospho-AKT, phospho-mTOR, p70 S6 kinase, phospho-p70 S6 kinase, S6, phospho-S6, 4E-BP1, and phospho-4E-BP1, using western blotting to determine whether the signaling pathway was affected by miR-124-3p. Notably, PI3K, phospho-AKT (Thr308), phosphomTOR (Ser2448), p70 S6 kinase, S6, 4E-BP1, and phospho-4E-BP1 (Thr37/46) levels decreased after miR-124-3p overexpression in CNE2 and 6-10B cells (Fig. 7A). In contrast, after inhibition of miR-124-3p expression in S18 and HK1 cells, PI3K, phospho-AKT (Thr308), phospho-mTOR (Ser2448), p70 S6 kinase, S6, 4E-BP1, and phospho-4E-BP1 (Thr37/46) levels were 
increased compared with those in the NC group (Fig. 7B). Thus, miR-124-3p overexpression decreased activation of the PI3K/AKT/mTOR signaling pathway and thereby inhibited the proliferation and growth of NPC cells (Fig. 7C).

\section{Discussion}

In this study, we found that miR-124-3p was significantly downregulated in NPC tissues compared with that in healthy tissues. Moreover, miR-124-3p expression inhibited the proliferation and growth of NPC cells in vitro and affected the $G_{1} / S$ transition. Overall, our findings demonstrated that miR-124-3p could inhibit the proliferation and growth of NPC cells by targeting and positively regulating PCDH8.

A

hsa-miR-124-3p 3'-aaccGUAAGUGGCGCACGGAAu-5'

\|\|\|\| $\mid \|$

PCDH8 5'-taaTATGCAAGATGTGCCTTa-3'

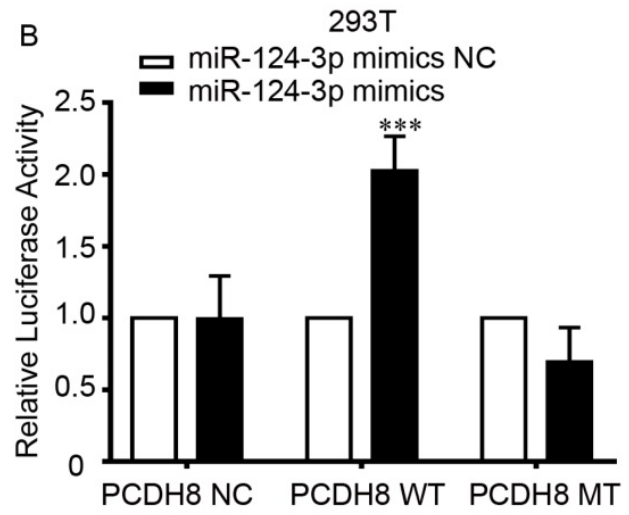

C

S18
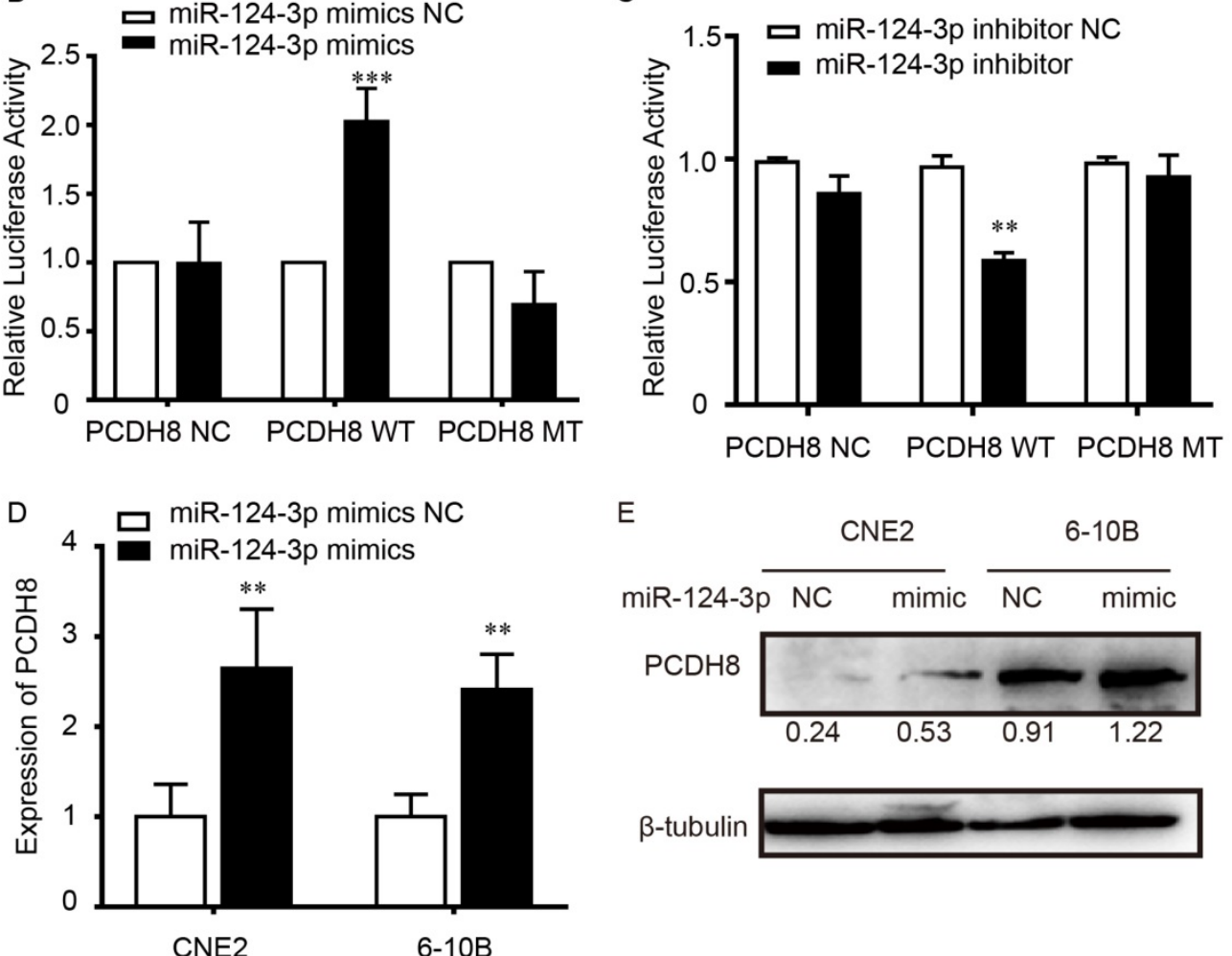

$\mathrm{E}$
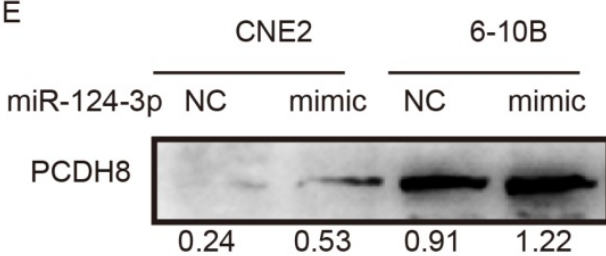

$\beta$-tubulin
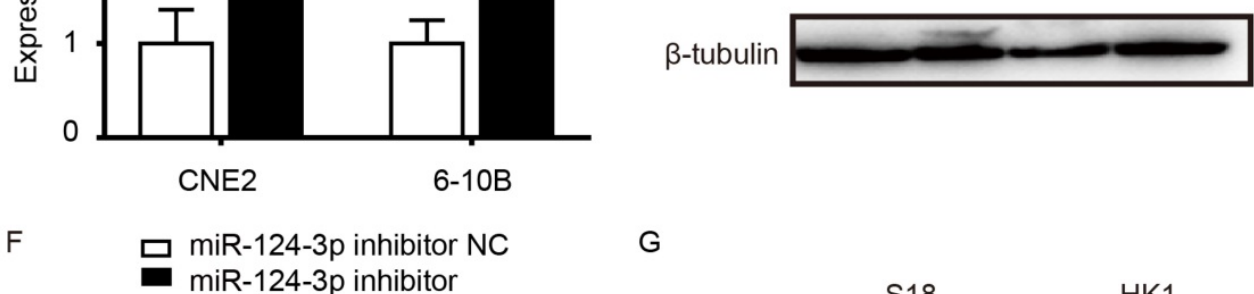

G
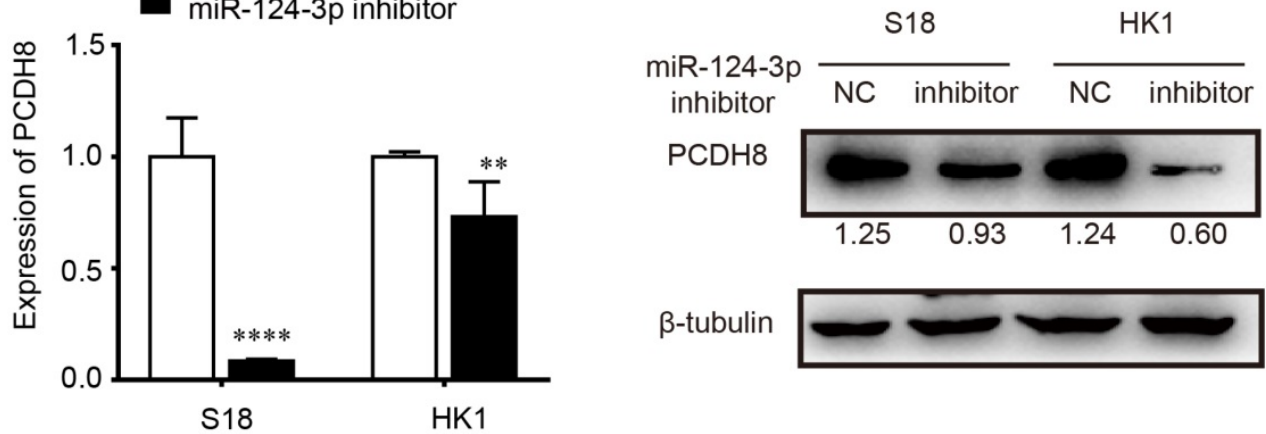

Figure 4. miR- $124-3 p$ positively regulated $P C D H 8$ by interacting with its 3 '-UTR. (A) The 3 '-UTR of $P C D H 8$ was a binding target for miR- $124-3 p$. (B) Effects of miR- $/ 24-3 p$ overexpression on firefly luciferase activity in $293 \mathrm{t}$ cells cotransfected with PCDH8-WT or -MUT. (C) Effects of miR- $124-3 p$ inhibitor on firefly luciferase activity in S18 cells cotransfected with PCDH8-WT or -MUT. (D and E) Effects of miR-I24-3p mimic in CNE2 and 6-10B cells on PCDH8 mRNA expression. (F and G) Effects of miR-I24-3p inhibitor in $\mathrm{S} 18$ and $\mathrm{HK} 1$ cells on $\mathrm{PCDH} 8 \mathrm{mRNA}$ expression. 
A

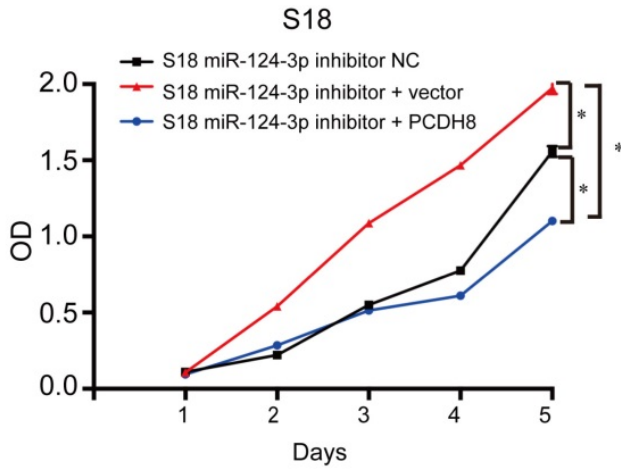

C S18 HK1
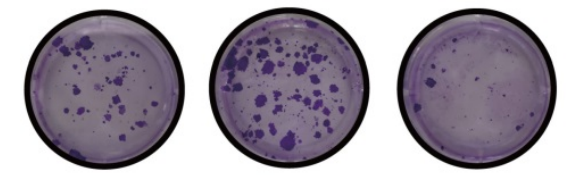

E

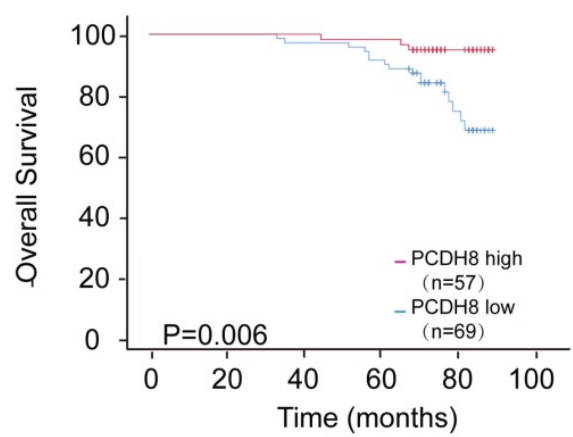

B

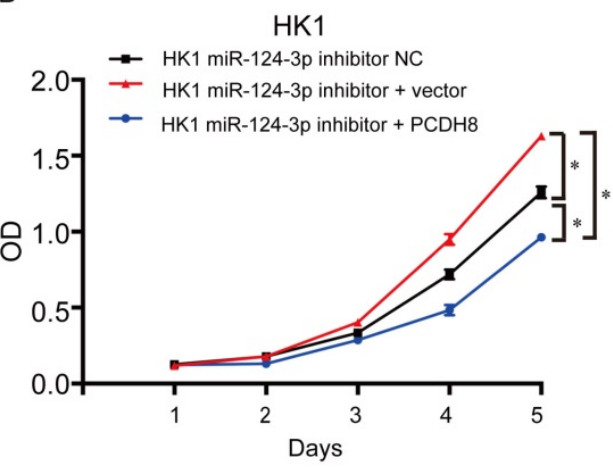

D
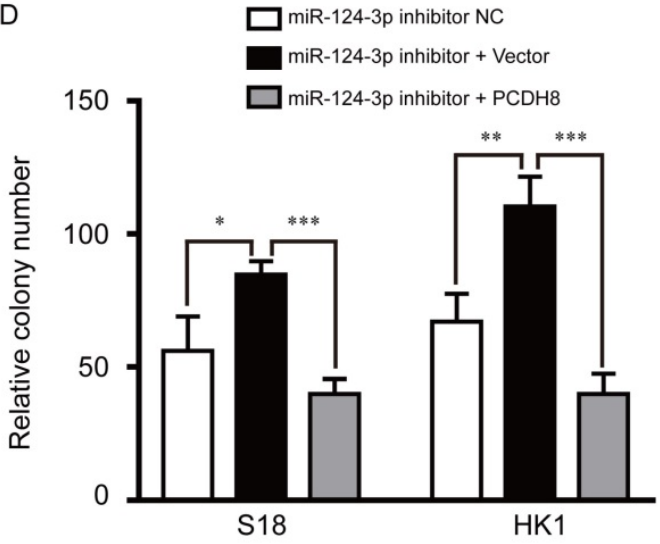

F

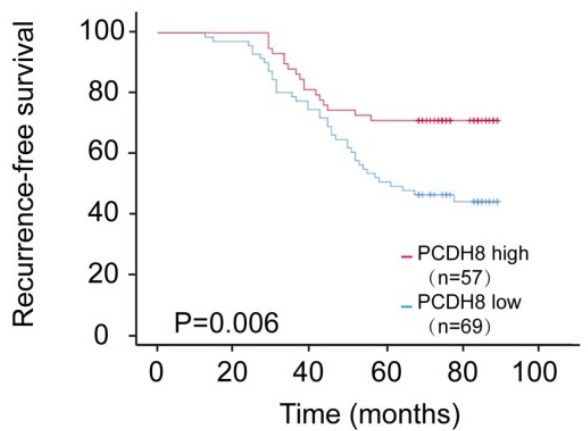

Figure 5. PCDH8 rescued the suppression of miR-124-3p in NPC cell lines. (A and B) Effects of miR-124-3p inhibitor treatment on cell proliferation in S18 cells (A) and HK1 cells (B). (C and D) Effects of miR-124-3p inhibitor on cell proliferation and colony formation. (E) Overall survival of nasopharyngeal carcinoma (NPC) patients with high or low PCDH8. (F) RFS of NPC patients with high or low PCDH8. Higher PCDH8 expression was associated with higher OS and RFS.

The abnormal expression of miR-124 is related to the regulation of important processes in various types of cancer, including cell proliferation, growth, apoptosis, and metastasis. For example, miR-124-3p directly targets the $3^{\prime}-\mathrm{UTR}$ of the mRNA encoding the branched chain amino acid transaminase-1, which suppresses the growth and invasion of esophageal squamous cell carcinoma [20]. Similarly, miR-124-3p blocks cell migration and invasion by affecting the combined integrin subunit alpha-3 signaling in bladder cancer [35]. Furthermore, Luo et al. reported that miR-124-3p suppressed the aggressiveness of glioma by targeting Fos-related antigen-2, suggesting potential applications of this miRNA in the treatment of this disease [21]. Liu et al. found that abnormal overexpression of miR-124-3p in gastric cancer cells could inhibit cell viability, colony formation, and tumor growth in vivo; therefore, $m i R-124-3 p$ may act as a potential marker and inhibit tumor growth in gastric cancer [36]. Additionally, Idichi et al. showed that miR-124-3 $p$ expression was low in pancreatic ductal adenocarcinoma tissues and that abnormal expression of miR-124-3p suppressed cancer cell migration and invasion in these tissues [37]. In our study, we found that $m i R-124-3 p$ expression was low in most NPC cell lines, but overexpression of miR-124-3p significantly inhibited proliferation and colony formation in these cell lines. Therefore, $m i R-124-3 p$ may act as a tumor suppressor in NPC. 
A

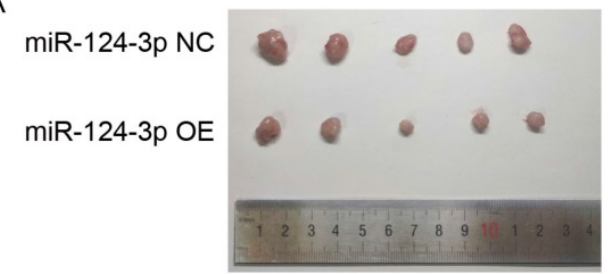

C

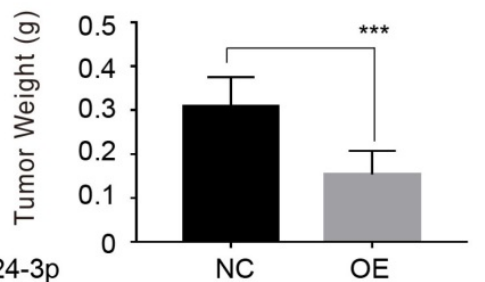

E

miR-124-3p

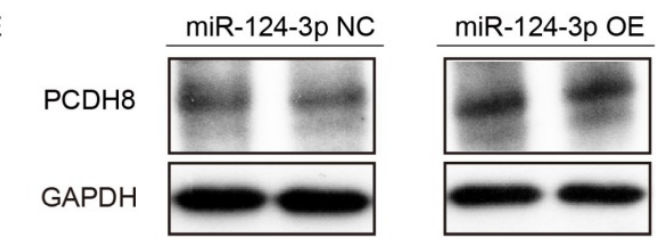

B

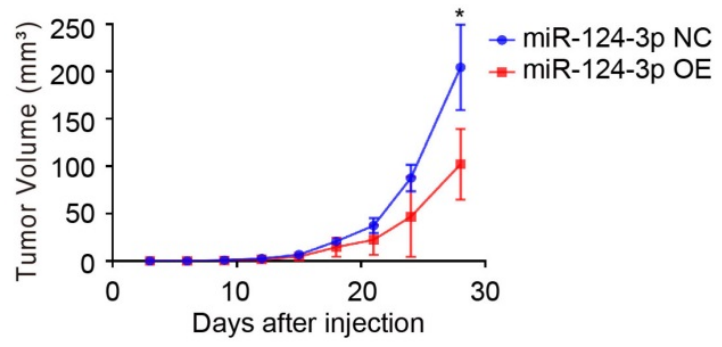

D



Figure 6. Upregulation of miR-I24-3p inhibit tumorigenesis of nasopharyngeal carcinoma cells in nude mice. (A) Four weeks after injected with CNE2 cell in subcutaneous on nude mice, the group of overexpressing miR-124-3p was significantly smaller than that formed by the CNE2 cells transfected with negative group. (B) The tumor volume of subcutaneously implanted tumor in nude mice with miR-I24-3p overexpression decreased significantly than negative group. (C) The weight of subcutaneously implanted tumor in nude mice with miR-I24-3p overexpression decreased significantly than negative group. (D) qPCR showed that the expression of miR-I24-3p in the subcutaneously transplanted tumor tissue was significantly increased in miR-I 24-3p overexpression group. (E) Western blot analysis indicated that the expression of PCDH8 was decreased in the subcutaneously transplanted tumor tissue in the miR-124-3p overexpression group.

A

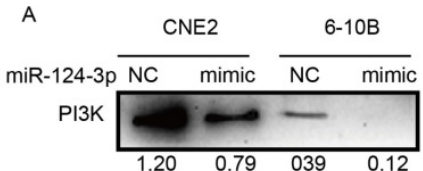

AKT
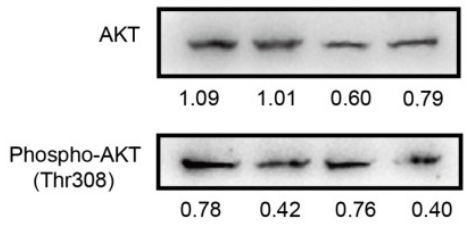

Phospho-mTOR (Ser2448)

4E-BP1

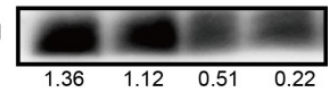

Phospho-4EBP1(Thr37/46)

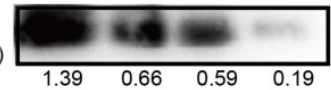

P70 S6

kinase

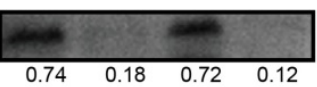

S6

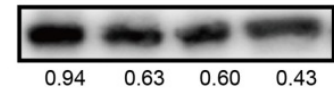

$\beta$-tubulin

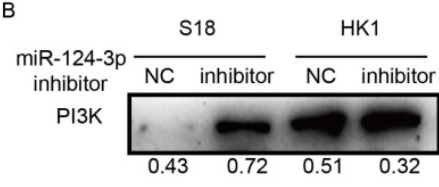

AKT


Phospho-mTOR

(Ser2448)

4E-BP1
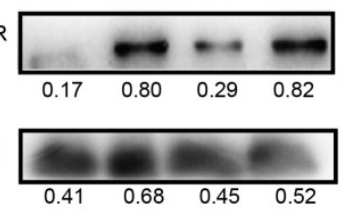

Phospho-4EBP1(Thr37/46)
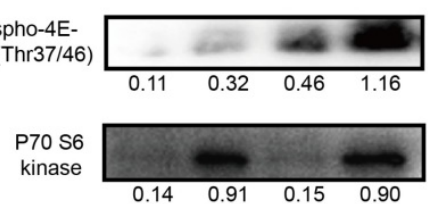

s6

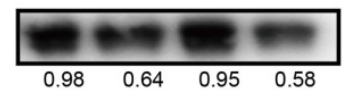

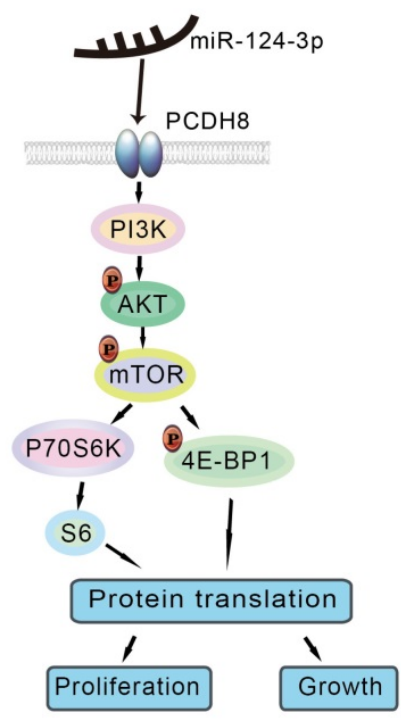

$\beta$-tubulin

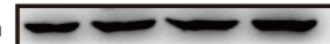

Figure 7. miR-124-3p inhibited the proliferation and growth of nasopharyngeal carcinoma cells through activation of the PI3K/AKT/mTOR signaling pathway. (A) Effects of miR-1 24-3p overexpression on the levels of PI3K, phospho-AKT (Thr308), phospho-mTOR (Ser2448), p70 S6 kinase, S6, 4E-BP1, and phospho-4E-BPI (Thr37/46) in CNE2 and 6-10B cells. (B) Effects of miR-I 24-3p inhibitor on PI3K, phospho-AKT (Thr308), phospho-mTOR (Ser2448), p70 S6 kinase, S6, 4E-BP1, and phospho-4E-BPI (Thr37/46) levels in S18 and HK1 cells. (C) miR-I 24-3p overexpression decreased activation of the PI3K/AKT/mTOR signaling pathway, thereby inhibiting the proliferation and growth of NPC cells. 
In a clinical trial, $\mathrm{PCDH} 8$ was inhibited in tumor tissues when compared with that in non-tumor tissues, particularly in patients with advanced hypopharyngeal carcinoma, suggesting that PCDH8 could be a prognostic biomarker and target for the treatment of this type of cancer [29]. Wang et al. found that PCDH8 was regulated by miR-217, which is involved in promoting apoptosis in small cell lung cancer [33]. Moreover, Cao et al. also showed that PCDH8 was involved in the metastasis of gastric cancer and that $\mathrm{PCDH} 8$ expression was lower in ovarian cancer tissues than in corresponding adjacent tissues, and contributed to the advanced progression of ovarian cancer [38]. Our findings showed that miR-124-3p positively regulated $P C D H 8$ expression through interactions with its 3'-UTR. Moreover, when NPC cells were transfected with a PCDH8 plasmid and then treated with miR-124-3p inhibitor, cell proliferation and colony formation decreased compared with that in the control group. These results indicated that overexpression of PCDH8 could partially rescue the suppressive activity of $m i R-124-3 p$ and that PCDH8 may also act as a tumor suppressor in NPC.

The PI3K/AKT/mTOR signaling pathway is involved in cell proliferation, growth, differentiation, and cytoskeletal reorganization in many types of cancer [39-41]. Our study showed that the overexpression of $m i R-124-3 p$ affected tumor progression in NPC cells through the PI3K/AKT/mTOR pathway. When miR-124-3p was overexpressed in CNE2 and 6-10B cells, the protein levels of phospho-mTOR, PI3K, p70 S6k, S6, and 4E-BP1 were decreased. These findings suggested that inhibition of NPC cell proliferation and growth by $m i R-124-3 p$ was mediated through the PI3K/AKT/mTOR pathway.

In conclusion, $m i R-124-3 p$ expression was low in NPC tissues and was associated with the tumor suppressor of NPC. Over expression of $m i R-124-3 p$ could decrease the abilities of proliferation and colony formation in NPC cells. Meanwhile, knockdown miR-124-3p increased proliferation and colony formation abilities. PCDH8 could partially rescue the proliferation and colony formation role of $m i R-124-3 p$ inhibitor. Our results confirmed that miR-124-3p overexpression significantly decreased the proliferation and colony formation of NPC cells by interacting with PCDH8 and inhibiting the activation of the phosphatidylinositol 3-kinase (PI3K)/AKT/ mammalian target of rapamycin (mTOR) signaling pathway. Thus, miR-124-3p and PCDH8 maybe potential molecular targets that impeded NPC proliferation and colony formation.

\section{Abbreviations}

NPC: Nasopharyngeal carcinoma; PCDH8: protocadherin-8; miRNA: microRNA; NC: negative control.

\section{Supplementary Material}

Supplementary tables.

http://www.jcancer.org/v12p4933s1.pdf

\section{Acknowledgements}

We thank Elsevier Webshop for assistance with language editing. We thank Guangzhou HongMai Biological Technology Co., Ltd. for animal laboratory assistance on animal experiment.

\section{Funding}

This study was supported by The Special Project on Development for Science and Technology of Guangdong Province, China (grant no. 2017ZC0264) and Guangzhou Health Science and technology project (grant no. 20201A011101), Key Clinical Technology of Guangzhou (grant no. 2019ZD17).

\section{Availability of data and materials}

The datasets used and/or analyzed in this study are available from the corresponding author upon reasonable request.

\section{Ethics approval and consent to participate}

This study was approved by the Affiliated Cancer Hospital \& Institute of Guangzhou Medical University.

\section{Author Contributions}

JY participated in the design of the study and drafted the manuscript. QL and $\mathrm{XZ}$ revised the manuscript and performed the western blotting and dual-luciferase reporter experiments. CL and YD performed the cell culture, cell transfection, CCK-8, and cell colony formation experiments. $\mathrm{XL}$ revised the manuscript and conducted the statistical analysis. LZ assisted with the design of the study and revised the manuscript. YY and TG conceived the study, participated in its design and coordination, and helped revise the manuscript. All authors read and approved the final version of the manuscript.

\section{Competing Interests}

The authors have declared that no competing interest exists.

\section{References}

1. Bray F, Ferlay J, Soerjomataram I, Siegel RL, Torre LA, Jemal A. Global cancer statistics 2018: GLOBOCAN estimates of incidence and mortality worldwide for 36 cancers in 185 countries. CA: a cancer journal for clinicians. 2018; 68: 394-424 
2. Kaidar-Person O, Gil Z, Billan S. Precision medicine in head and neck cancer. Drug resistance updates : reviews and commentaries in antimicrobial and anticancer chemotherapy. 2018; 40: 13-6.

3. Tang LL, Chen WQ, Xue WQ, He YQ, Zheng RS, Zeng YX, et al. Global trends in incidence and mortality of nasopharyngeal carcinoma. Cancer letters. 2016; 374: 22-30.

4. Chen YP, Chan ATC, Le QT, Blanchard P, Sun Y, Ma J. Nasopharyngeal carcinoma. Lancet. 2019; 394: 64-80.

5. Kamran SC, Riaz N, Lee N. Nasopharyngeal carcinoma. Surg Oncol Clin N Am. 2015; 24: 547-61.

6. Holliday EB, Frank SJ. Proton radiation therapy for head and neck cancer: a review of the clinical experience to date. Int J Radiat Oncol Biol Phys. 2014; 89: 292-302.

7. Holliday EB, Frank SJ. Proton therapy for nasopharyngeal carcinoma. Chin Clin Oncol. 2016; 5: 25

8. Lewis GD, Holliday EB, Kocak-Uzel E, Hernandez M, Garden AS, Rosenthal DI, et al. Intensity-modulated proton therapy for nasopharyngeal carcinoma: Decreased radiation dose to normal structures and encouraging clinical outcomes. Head Neck. 2016; 38 Suppl 1: E1886-95.

9. Liu SC, Huang CM, Chang YL, Bamodu OA, Yeh CT, Wang HW, et al. Ovatodiolide suppresses inflammatory response in BEAS-2B cells by regulating the CREB/AQP5 pathway, and sensitizes nasopharyngeal carcinoma cells to radiation therapy. European journal of pharmacology. 2019; 859: 172548

10. Chen CH, Su LJ, Tsai HT, Hwang CF. ELF-1 expression in nasopharyngeal carcinoma facilitates proliferation and metastasis of cancer cells via modulation of CCL2/CCR2 signaling. Cancer management and research. 2019; 11: 5243-54.

11. Zheng ZQ, Li ZX, Zhou GQ, Lin L, Zhang LL, Lv JW, et al. Long Noncoding RNA FAM225A Promotes Nasopharyngeal Carcinoma Tumorigenesis and Metastasis by Acting as ceRNA to Sponge miR-590-3p/miR-1275 and Upregulate ITGB3. Cancer research. 2019; 79: 4612-26.

12. Zendjabil M, Favard S, Tse C, Abbou O, Hainque B. [The microRNAs as biomarkers: What prospects?]. C R Biol. 2017; 340: 114-31.

13. Kumarasamy C, Madhav MR, Sabarimurugan S, Krishnan S, Baxi S, Gupta A, et al. Prognostic Value of miRNAs in Head and Neck Cancers: A Comprehensive Systematic and Meta-Analysis. Cells. 2019; 8 .

14. Ahmad P, Sana J, Slavik M, Slampa P, Smilek P, Slaby O. MicroRNAs Involvement in Radioresistance of Head and Neck Cancer. Dis Markers. 2017; 2017: 8245345

15. Rasnic R, Linial N, Linial M. Enhancing identification of cancer types via lowly-expressed microRNAs. Nucleic Acids Res. 2017; 45: 5048-60.

16. Yu L, Lu J, Zhang B, Liu X, Wang L, Li SY, et al. miR-26a inhibits invasion and metastasis of nasopharyngeal cancer by targeting EZH2. Oncology letters. 2013; 5: 1223-8.

17. Wu RS, Qiu EH, Zhu JJ, Wang JR, Lin HL. MiR-101 promotes nasopharyngeal carcinoma cell apoptosis through inhibiting Ras/Raf/MEK/ERK signaling pathway. European review for medical and pharmacological sciences. 2018; 22. $150-7$

18. Liu J, Chen W, Chen Z, Wen J, Yu H, Wang F, et al. The effects of microRNA-98 inhibits cell proliferation and invasion by targeting STAT3 in nasopharyngeal carcinoma. Biomedicine \& pharmacotherapy $=$ Biomedecine \& pharmacotherapie. 2017; 93: 869-78

19. Guo J, Ma J, Zhao G, Li G, Fu Y, Luo Y, et al. Long Noncoding RNA LINC0086 Functions as a Tumor Suppressor in Nasopharyngeal Carcinoma by Targeting miR-214. Oncol Res. 2017; 25: 1189-97.

20. Zeng B, Zhang $X$, Zhao J, Wei Z, Zhu H, Fu M, et al. The role of DNMT1/hsa-miR-124-3p/BCAT1 pathway in regulating growth and invasion of esophageal squamous cell carcinoma. BMC cancer. 2019; 19: 609.

21. Luo L, Chi H, Ling J. MiR-124-3p suppresses glioma aggressiveness via targeting of Fra-2. Pathol Res Pract. 2018; 214: 1825-34.

22. Cheng N, Guo Y. Long noncoding RNA NEAT1 promotes nasopharyngeal carcinoma progression through regulation of miR-124/NF-kappaB pathway. OncoTargets and therapy. 2017; 10:5843-53.

23. Du M, Chen $\mathrm{W}$, Zhang $\mathrm{W}$, Tian XK, Wang $\mathrm{T}$, Wu J, et al. TGF-? regulates the ERK/MAPK pathway independent of the SMAD pathway by repressing miRNA-124 to increase MALAT1 expression in nasopharyngeal carcinoma. Biomedicine \& pharmacotherapy = Biomedecine \& pharmacotherapie. 2018; 99: 688-96.

24. $\mathrm{Hu} \mathrm{H}$, Wang G, Li C. miR-124 suppresses proliferation and invasion of nasopharyngeal carcinoma cells through the Wnt/beta-catenin signaling pathway by targeting Capn4. OncoTargets and therapy. 2017; 10: 2711-20.

25. Peng XH, Huang HR, Lu J, Liu X, Zhao FP, Zhang B, et al. MiR-124 suppresses tumor growth and metastasis by targeting Foxq1 in nasopharyngeal carcinoma. Molecular cancer. 2014; 13: 186.

26. Shi B, Wang Y, Yin F. MALAT1/miR-124/Capn4 axis regulates proliferation, invasion and EMT in nasopharyngeal carcinoma cells. Cancer biology \& therapy. 2017; 18: 792-800.

27. $\mathrm{Xu} X$, Lu J, Wang $F$, Liu $X$, Peng $X, Y u$, et al. Dynamic Changes in Plasma MicroRNAs Have Potential Predictive Values in Monitoring Recurrence and Metastasis of Nasopharyngeal Carcinoma. BioMed research international. 2018; 2018: 7329195.

28. Xu S, Zhao N, Hui L, Song M, Miao ZW, Jiang XJ. MicroRNA-124-3p inhibits the growth and metastasis of nasopharyngeal carcinoma cells by targeting STAT3. Oncology reports. 2016; 35: 1385-94.
29. Li Y, Liu C, Wang Z, Hu G. Expression of protocadherin8: Function as a tumor suppressor in hypopharyngeal carcinoma. Cancer biomarkers : section A of Disease markers. 2018; 22: 495-502.

30. Lin YL, Li YL, Ma JG. Aberrant Promoter Methylation of Protocadherin8 (PCDH8) in Serum is a Potential Prognostic Marker for Low Gleason Score Prostate Cancer. Med Sci Monit. 2017; 23: 4895-900.

31. Zhang C, Peng Y, Yang F, Qin R, Liu W, Zhang C. PCDH8 is Frequently Inactivated by Promoter Hypermethylation in Liver Cancer: Diagnostic and Clinical Significance. Journal of Cancer. 2016; 7: 446-52.

32. Lin $\mathrm{Y}$, Ge X, Zhang X, Wu Z, Liu K, Lin F, et al. Protocadherin-8 promotes invasion and metastasis via laminin subunit gamma 2 in gastric cancer. Cancer science. 2018; 109: 732-40

33. Wang B, Chen X, Zhu X, Ma D. MicroRNA-217 inhibits proliferation and promotes apoptosis of small cell lung cancer cells via targeting PCDH8. Panminerva Med. 2019; 63:95-96.

34. He D, Zeng Q, Ren G, Xiang T, Qian Y, Hu Q, et al. Protocadherin8 is a functional tumor suppressor frequently inactivated by promoter methylation in nasopharyngeal carcinoma. European journal of cancer prevention : the official journal of the European Cancer Prevention Organisation. 2012; 21: 569-75.

35. Wang JR, Liu B, Zhou L, Huang YX. MicroRNA-124-3p suppresses cell migration and invasion by targeting ITGA3 signaling in bladder cancer. Cancer biomarkers : section A of Disease markers. 2019; 24: 159-72.

36. Liu $\mathrm{F}, \mathrm{Hu} \mathrm{H}$, Zhao J, Zhang Z, Ai X, Tang L, et al. miR-124-3p acts as a potential marker and suppresses tumor growth in gastric cancer. Biomed Rep. 2018; 9: 147-55

37. Idichi T, Seki N, Kurahara H, Fukuhisa H, Toda H, Shimonosono M, et al. Involvement of anti-tumor miR-124-3p and its targets in the pathogenesis of pancreatic ductal adenocarcinoma: direct regulation of ITGA3 and ITGB1 by miR-124-3p. Oncotarget. 2018; 9: 28849-65.

38. Cao Y, Yu Y, Chen X, Ren F, Zhang R, Jia Y, et al. Low Expression of Protocadherin-8 Promotes the Progression of Ovarian Cancer. Int J Gynecol Cancer. 2018; 28: 346-54.

39. Chen Q, Zheng W, Zhu L, Yao D, Wang C, Song Y, et al. ANXA6 Contributes to Radioresistance by Promoting Autophagy via Inhibiting the PI3K/AKT/mTOR Signaling Pathway in Nasopharyngeal Carcinoma. Front Cell Dev Biol. 2020; 8: 232.

40. Ediriweera MK, Tennekoon $\mathrm{KH}$ Samarakoon SR Role of the PI3K/AKT/mTOR signaling pathway in ovarian cancer: Biological and therapeutic significance. Semin Cancer Biol. 2019; 59: 147-60.

41. Guerrero-Zotano A, Mayer IA, Arteaga CL. PI3K/AKT/mTOR: role in breast cancer progression, drug resistance, and treatment. Cancer Metastasis Rev. 2016; 35: 515-24 